\title{
The public health benefits of insulation retrofits in existing housing in the United States
}

\author{
Jonathan I Levy*, Yurika Nishioka and John D Spengler
}

Address: Department of Environmental Health, Harvard School of Public Health, Boston, MA, USA

Email: Jonathan I Levy* - jilevy@hsph.harvard.edu; Yurika Nishioka - ynishiok@hsph.harvard.edu; John D Spengler - spengler@hsph.harvard.edu

* Corresponding author

Published: II April 2003

Environmental Health: A Global Access Science Source 2003, 2:4

This article is available from: http://www.ehjournal.net/content/2/l/4

(C) 2003 Levy et al; licensee BioMed Central Ltd. This is an Open Access article: verbatim copying and redistribution of this article are permitted in all media for any purpose, provided this notice is preserved along with the article's original URL.

Received: 2 January 2003

Accepted: II April 2003

\begin{abstract}
Background: Methodological limitations make it difficult to quantify the public health benefits of energy efficiency programs. To address this issue, we developed a risk-based model to estimate the health benefits associated with marginal energy usage reductions and applied the model to a hypothetical case study of insulation retrofits in single-family homes in the United States.
\end{abstract}

Methods: We modeled energy savings with a regression model that extrapolated findings from an energy simulation program. Reductions of fine particulate matter $\left(\mathrm{PM}_{2.5}\right)$ emissions and particle precursors $\left(\mathrm{SO}_{2}\right.$ and $\left.\mathrm{NOx}\right)$ were quantified using fuel-specific emission factors and marginal electricity analyses. Estimates of population exposure per unit emissions, varying by location and source type, were extrapolated from past dispersion model runs. Concentration-response functions for morbidity and mortality from $\mathrm{PM}_{2.5}$ were derived from the epidemiological literature, and economic values were assigned to health outcomes based on willingness to pay studies.

Results: In total, the insulation retrofits would save 800 TBTU $\left(8 \times 10^{14}\right.$ British Thermal Units $)$ per year across 46 million homes, resulting in 3,100 fewer tons of $\mathrm{PM}_{2.5}, 100,000$ fewer tons of $\mathrm{NOx}$, and 190,000 fewer tons of $\mathrm{SO}_{2}$ per year. These emission reductions are associated with outcomes including 240 fewer deaths, 6,500 fewer asthma attacks, and 110,000 fewer restricted activity days per year. At a state level, the health benefits per unit energy savings vary by an order of magnitude, illustrating that multiple factors (including population patterns and energy sources) influence health benefit estimates. The health benefits correspond to $\$ 1.3$ billion per year in externalities averted, compared with $\$ 5.9$ billion per year in economic savings.

Conclusion: In spite of significant uncertainties related to the interpretation of $\mathrm{PM}_{2.5}$ health effects and other dimensions of the model, our analysis demonstrates that a risk-based methodology is viable for national-level energy efficiency programs.

\section{Background}

Generally, the benefits of energy efficiency programs are expressed in terms of the economic payback that will accrue for individuals or organizations. To introduce environmental benefits into this framework, some investigators have quantified the emission reductions related to the decreased use of electricity and fossil fuel $[1,2]$, including criteria air pollutants and greenhouse gases. While these analyses are useful, they provide only a limited set of information, as issues such as pollutant fate 
and transport or pollutant toxicity are omitted, making environmental and economic endpoints incomparable.

Multiple studies have developed models to estimate the health impacts of emissions from specific sources, using a risk-based approach to link emissions of key pollutants with dispersion models and health evidence [3-6]. While this is a valuable approach, it can be difficult to apply in the case of broad-based energy efficiency programs, as these programs tend to affect multiple sources simultaneously (e.g., numerous homes within a state, all power plants on the grid). Quantifying the health benefits of energy efficiency programs therefore requires a simplified approach toward risk calculations, with adequate characterization of uncertainty to aid in the interpretation of the findings.

In a recent investigation [7], we developed a model to predict the public health benefits of increased residential insulation in new housing, related to the emission reductions of fine particulate matter $\left(\mathrm{PM}_{2.5}\right)$ and its precursors (nitrogen dioxide and sulfur dioxide). We determined that increasing insulation from current practice to the latest International Energy Conservation Code (IECC 2000) levels for all single-family homes built from 2001 to 2010 would save 300 TBTU $\left(3 \times 10^{14}\right.$ British Thermal Units) during the ten-year period ( 5 TBTU for the annual housing output per year). Linking this evidence with estimated emission reductions, extrapolated results from dispersion model outputs and epidemiological evidence, we concluded that the resulting public health benefits would include approximately 60 fewer deaths, 2,000 fewer asthma attacks, and 30,000 fewer restricted activity days within this decade ( 1.1 deaths, 30 asthma attacks, and 500 restricted activity days reduced per year for all new homes built in 2001).

Although this investigation demonstrated that a riskbased methodology for demand-side management programs is viable and provided a crucial foundation for policy analysis, interpretation was impaired by the relatively narrow focus. For example, the new housing market represents only a small fraction of the potential public health benefits of insulation in the residential sector. There are approximately 1.2 million new single-family homes built each year [8], but the existing housing stock consists of more than 75 million single-family homes. Furthermore, it would be anticipated that there is greater per unit potential for energy savings in existing housing, given many homes built prior to the promulgation of energy codes that therefore contain relatively less insulation than newer homes.

In spite of the anticipated greater energy savings of the existing versus new housing market, the relative public health benefits will not necessarily be proportional. Because the geographic distribution of housing starts differs from the distribution of existing homes, geographic patterns of energy savings will differ. There are regional differences in population density and meteorological patterns, both of which will influence the magnitude of health benefits. The fuels used in homes also differ both regionally and by age of home, which will strongly influence emissions. In this paper, we apply our risk model to the existing single-family home market in the United States to evaluate the following questions:

- What are the magnitude and distribution of public health benefits associated with hypothetically retrofitting single-family homes with insulation at IECC 2000 levels when necessary?

- How does the economic value associated with these public health benefits compare with the economic savings for the households?

- In general, how uncertain are public health benefit estimates derived from simplified models, and what are the major contributors to that uncertainty?

\section{Methods}

Estimating the public health benefits of increased insulation in existing housing requires multiple discrete steps. First, we quantify the state-by-state energy savings available through increased residential insulation. We use information about regional residential fuel utilization patterns and power plant emissions to determine the emission reductions associated with these energy savings. These emission reductions are combined with summary findings from national-scale dispersion models and epidemiological studies to yield estimates of the public health benefits, and economic values are placed on health outcomes to allow for a direct comparison with cost savings. As many elements of this framework have been described elsewhere [7], we highlight the key elements of the methodology or those which are unique to this analysis.

Although any investigation of this sort contains significant uncertainties and should be considered incomplete without detailed uncertainty analysis, we provide only central estimates with general assessments of the magnitudes of various uncertainties within the Discussion section. Quantitative uncertainty analysis is impaired by the difficulty of adequately estimating uncertainty for components such as the aggregate national exposures per unit emissions and the likelihood that the epidemiological evidence reflects a causal relationship, and is beyond the scope of this analysis. A more detailed discussion of uncertainty within our analytical framework is available elsewhere $[4,7]$. 
Table I: Current insulation levels in existing single-family homes by census division [13] (batt insulation assumed for all).

\begin{tabular}{lllllllllll}
\hline & NE & MA & SA & ESC & WSC & ENC & WNC & MTN & PA \\
\hline Ceiling & R-30 & R-30 & R-II & R-II & R-II & R-19 & R-19 & R-19 & R-I \\
Above-grade wall & R-II & R-1I & R-6 & R-6 & R-6 & R-II & R-1I & R-II & R-6 \\
Floor & R-13 & R-13 & R-3.4 & R-3.4 & R-3.4 & R-II & R-II & R-1I & R-5.5 \\
\hline
\end{tabular}

Definitions of census divisions: NE (Northeast): MA, ME, NH, VT, RI, CT; MA (Mid-Atlantic): NY, PA, NJ; SA (South-Atlantic): MD, VA, WV, DC, NC, SC, GA, FL; ESC (East-South-Central): AL, MS, KY, TN; WSC (West-South-Central): TX, OK, AR, LA; ENC (East-NorthCentral): MI, IL, OH, IN, WI; WNC (West-North-Central): MO, IA, MN, SD, ND, NE, KS; MTN (Mountain): ID, MT, NV, AZ, NM, UT, CO, WY; PA (Pacific): CA, OR, WA. Note: The R-value represents the resistance of the insulation to heat flow, with higher values indicating greater resistance. $R$-values are given in units of ${ }^{\circ} \mathrm{F} . \mathrm{ft} 2 . \mathrm{h} / \mathrm{BTU}$.

In addition, it is important to note that our stated methodology contains some implicit boundary conditions. For example, we do not attempt to characterize the life cycle impacts of increased insulation manufacturing and decreased fuel production within this article. This implies that we are quantifying the public health benefits of reduced energy consumption related to increased insulation, but do not know the degree to which this might be offset by increased emissions from insulation manufacturing (or augmented by upstream benefits from decreased fuel utilization). A detailed exploration of this question in the new housing market indicates that the upstream manufacturing emissions are offset by the energyrelated public health benefits with a payback period nearly identical to the economic payback period for homeowners $[9,10]$. This analysis focused exclusively on the emissions associated with inputs to insulation manufacturing and fuel production, and did not consider dimensions such as occupational risks, installation risks, or indoor air quality. Finally, it should be noted that we assume for the sake of simplicity that all existing homes are retrofitted with insulation immediately, which has implications for the interpretation of our findings.

\section{Energy Savings}

To quantify the energy savings associated with insulation retrofits in existing single-family homes, we use a regression-based approach to simulate energy savings in a number of prototype homes in different cities and apply those findings to the set of homes where insulation retrofits were deemed plausible. The first step was to determine the number of homes in each state that likely require increased insulation. Using information from the Residential Energy Consumption Survey (RECS) [11], we estimated the total number of homes by state in 1999 . RECS also provided the percentage of single-family homes by census division, yielding an estimated 74 million single-family homes in the continental US.

We used the qualitative characterization of insulation levels by age of home within an earlier version of RECS [12] to determine the proportion of homes where insulation retrofits were viable. Homes that were well insulated were assumed to not require additional insulation, while homes with adequate or poor insulation were assumed to require more insulation. On average, $63 \%$ of single-family homes had adequate or poor insulation. Lacking geographically resolved information on this parameter, we assumed that this percentage applied to all states, yielding the number of target single-family homes at a state level (and approximately 46 million homes nationally). It should be noted that an assumption of geographic uniformity stratified by age of home yielded essentially identical estimates (ranging from 59\% in the South-Atlantic to $65 \%$ in New England, with census divisions defined as in Table 1), so this is unlikely to contribute to significant uncertainty in the analysis.

To quantify energy consumption under current conditions and given insulation increased to IECC 2000 levels, we applied regression models we developed originally for our new housing investigation [7]. We simulated prototype single-family homes in a number of different cities and applied the energy model REM/Design (Architectural Energy Corporation, Boulder, $\mathrm{CO}$ ) to estimate energy consumption given home configuration, climate, and insulation levels. We gathered current practice insulation levels (in ceiling, wall, and floor) from an earlier energy analysis [13], which assumed existing home insulation levels to be uniform within census divisions (Table 1). IECC 2000 insulation levels [14] are based on heating degree days rather than geographic region and are represented in Figure 1.

In addition, window types (metal versus wood), door thickness, and shading factors varied by region. Selected home characteristics as well as heating and cooling system features were assumed to be uniform nationally. This included unconditioned basements, exposed ducts, an infiltration rate of 0.67 , a heating set point of 20 degrees $\mathrm{C}$ ( 68 degrees $\mathrm{F}$ ), and a cooling set point of 26 degrees $\mathrm{C}$ (78 degrees F). Remaining home characteristics, including floor area, heating types, and number of stories by region, 


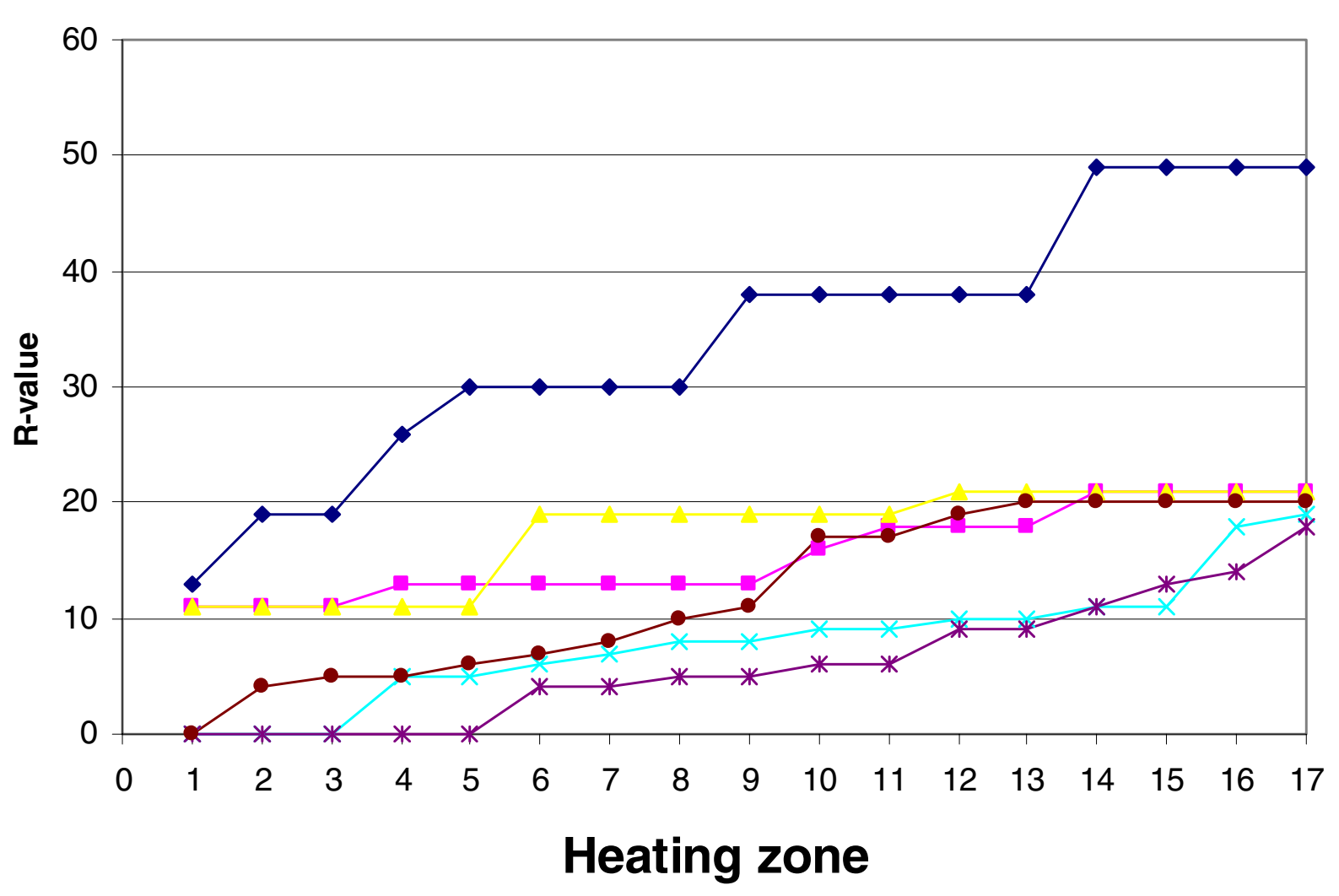

$\multimap$ Ceiling $\multimap-$ Exterior wall $\_$Floor $\multimap$ Basement $\rightarrow$ Slab $\multimap-$ Crawl

Figure I

R-values required in the 2000 International Energy Conservation Code by heating degree day zone [14].

were gathered from RECS [12]. Additional specifications of house or heating and cooling system characteristics are available from the authors upon request.

To ensure that the regression models represented the physical realities of heat transfer, the functional form of our regressions and the covariates selected were based on standard heat loss equations [15]. For example, space heating energy consumption was predicted as a function of two covariates - the product of heating degree days and floor area, and the product of heating degree days, floor area, and an expression reflecting the amount of insulation in the ceiling, walls, and floor $\left(\mathrm{R}^{2}=0.99\right)$. Finally, we calibrated the outputs from the regression models against reported energy consumption data from RECS to better reflect actual consumption patterns.

\section{Emission Reductions}

Given state-level energy savings by fuel type, we estimate emissions of primary $\mathrm{PM}_{2.5}, \mathrm{SO}_{2}$ (as a precursor of sulfate particles), and NOx (as a precursor of nitrate particles). This choice was based on the findings of past studies, in which PM contributed the vast majority of benefits $[16,17]$. As might be anticipated, our procedure to model emissions differs for direct residential fuel combustion 
and electricity. We summarize our approach below and refer the reader to our earlier analysis [7] for more detail.

For direct residential fuel combustion, given the fuel type (natural gas or fuel oil), we estimate emissions from the AP-42 database prepared by US EPA [18]. For fuel oil, emissions of both $\mathrm{SO}_{2}$ and PM are given as a function of the sulfur content in the fuel. Although the sulfur content of fuel oil can vary somewhat on a state-by-state basis, lacking detailed information, we assumed that a $0.5 \%$ sulfur content by weight was applicable nationally, as has been done previously [19].

On the other hand, for electricity, we needed to determine which power plants would be affected by marginal decreases in electricity consumption, since it is likely that the marginal plants are not identical to the average plants in the power pool. In our earlier analysis [7], we concluded that only non-combined cycle fossil-fuel plants with less than $80 \%$ capacity factors were likely to be influenced by small demand changes in the near term, as any base load units running at high capacity or units with supply-related constraints (e.g., nuclear, hydroelectric) could not respond to these changes. We applied these screening criteria to the Emissions and Generation Resource Integrated Database (E-GRID) [20] to determine a subset of 553 power plants potentially able to respond to demand-side management efforts. Without a detailed simulation of the electricity sector, it is impossible to determine precisely which plants would respond on the margin. For our central estimate, we assumed that each plant with positive net generation was equally likely to be affected, regardless of capacity or relative availability. It should be noted that this assumption resulted in lower emission rates than a capacity- or availability-based allocation, potentially biasing our estimates downward. The magnitude of this effect is considered in the Discussion section.

To link this information with electricity savings at the state level, we first quantified emissions of $\mathrm{NOx}$ and $\mathrm{SO}_{2}$ per unit output for each power plant using data from E-GRID. Since primary PM emissions were not incorporated into EGRID, we estimated $\mathrm{PM}_{2.5}$ emissions using AP-42 emission factors for $\mathrm{PM}_{10}$ (given power plant characteristics) and estimates of the $\mathrm{PM}_{2.5} / \mathrm{PM}_{10}$ emissions ratio. We used this information to determine emission factors by North American Electricity Reliability Council (NERC) region, and determined state-level emission factors based on the proportion of electricity consumption provided by each NERC region [18].

\section{Exposure Reductions}

As alluded to above, a critical (and difficult) step in accurately quantifying the health benefits of demand-side management efforts involves linking emissions savings to exposure reductions, given the substantial number of sources and limited capacity of fate and transport models. Recently, the risk assessment and atmospheric modeling communities have recognized the importance of developing approaches to extrapolate estimates from other studies in situations where input data are limited or comprehensive models are impractical. Multiple studies have developed and applied a concept known as an intake fraction, generally defined as the fraction of a pollutant or its precursor emitted that is eventually inhaled by someone $[21,22]$. Mathematically, an intake fraction can be calculated using the following equation:

$i F=\frac{B R \times \sum_{i} C_{i} \times N_{i}}{Q}$

where $i F=$ intake fraction; $B R=$ population-average breathing rate (assumed to be $20 \mathrm{~m}^{3} /$ day); $C_{i}=$ incremental concentration of pollutant at receptor $i\left(\mu \mathrm{g} / \mathrm{m}^{3}\right) ; N_{i}=$ number of people at receptor $i ; \mathrm{Q}=$ emission rate of pollutant or pollutant precursor $(\mu \mathrm{g} /$ day $)$. If the health effect in question has a linear dose-response function with no threshold above current ambient concentrations, an intake fraction provides an estimate directly interpretable from a health perspective (since the health impacts will be proportional to the sum of the product of population and concentration).

To apply the intake fraction concept in our investigation, we used predictive regression models developed in a recent study [23]. This study took its intake fraction estimates from an analysis [22] that used CALPUFF (a regional-scale Lagrangian puff model) to calculate intake fractions for primary $\mathrm{PM}_{2.5}$, sulfate particles (from $\mathrm{SO}_{2}$ ), and nitrate particles (from NOx), evaluating 40 power plants and 40 mobile sources distributed across the US. In general, the intake fractions were strongly predicted by population variables (e.g., population within 500 or 1000 $\mathrm{km}$ of a source), stack height (for primary $\mathrm{PM}_{2.5}$ from power plants), and miscellaneous meteorological terms (including annual average temperature, wind speed, relative humidity, or mixing height).

To apply these regressions to the power sector, we determined the values of the appropriate covariates for each marginal power plant identified above, resulting in intake fraction estimates for each of 553 power plants. To assign a representative intake fraction for electricity savings in each state, we weighted the plant-level intake fractions by emissions within NERC region and averaged across NERC regions in proportion to electricity transmission patterns. For residential combustion sources, we assumed that the mobile source intake fraction estimates were applicable 
(given emissions at or near ground level) and calculated intake fractions for each Metropolitan Statistical Area (MSA) across the US. State-level intake fractions were then estimated as a weighted average of MSA-level intake fractions, weighting by number of homes.

It should be noted that, in addition to the uncertainties associated with the regression model, there are overarching uncertainties associated with the application of CALPUFF. For example, although it is well established that changes in $\mathrm{SO}_{2}$ emissions can influence nitrate particle concentrations by affecting available ammonia levels [24], CALPUFF does not capture this phenomenon for an analysis of a small subset of sources. The importance of this effect and related model uncertainties are considered in the Discussion section.

\section{Public Health Benefits}

As in our past investigation [7], we quantify mortality and selected morbidity benefits associated with incremental reductions in $\mathrm{PM}_{2.5}$ exposures. Premature mortality associated with $\mathrm{PM}_{2.5}$ has typically dominated public health benefits when health endpoints were placed in economic terms $[16,17]$, but we include some morbidity endpoints to illustrate outcomes with varying severity. Although excluding the complete array of morbidity endpoints will result in a systematic underestimation of benefits, we adopt this approach for the sake of brevity. As mentioned above, given the framing of our analysis, we determine reasonable central estimates for concentration-response functions and consider the magnitude of the uncertainty in the Discussion section.

For premature mortality, we derive our central estimate from a follow-up analysis of the American Cancer Society cohort study [25]. This investigation followed approximately 500,000 individuals across a 16 -year period, evaluating mortality risk from air pollution while controlling for numerous plausible confounders (including smoking, alcohol consumption, body mass index, diet, and occupational exposures). Using pollution data averaged across the study period, the authors report a relative risk for allcause mortality of 1.06 for a $10 \mu \mathrm{g} / \mathrm{m}^{3}$ increase in $\mathrm{PM}_{2.5}$ concentrations (95\% CI: 1.02, 1.11). Alternatively, using pollution data from the start of the study period, the corresponding relative risk was 1.04 (95\% CI: 1.01, 1.08). Based on these estimates and given the desire to provide a parallel estimate with our earlier investigation to improve comparability [7], we apply a concentration-response function of a $0.5 \%$ increase in premature deaths per $\mu \mathrm{g} /$ $\mathrm{m}^{3}$ increase in annual mean $\mathrm{PM}_{2.5}$ concentrations. We consider this value to be a plausible central estimate, as it is bounded above by the concentration-response function from the Harvard Six Cities Study [26] and below by values from time-series studies.
As previously [7], we derive our selected morbidity concentration-response estimates from recent US EPA benefit-cost analyses $[16,17]$. This results in an estimated $0.2 \%$ increase in daily asthma attacks (among asthmatics only) and a $0.5 \%$ increase in restricted activity days per $\mu \mathrm{g} / \mathrm{m}^{3}$ increase in $\mathrm{PM}_{2.5}$ concentrations.

The application of concentration-response functions as described above implicitly assumes that no population threshold exists at current ambient concentrations in the US and that all forms of particulate matter have identical toxicity. The former assumption is bolstered by the lack of documented thresholds in both cohort $[25,26]$ and timeseries mortality $[27,28]$ investigations. Consideration of the latter issue is beyond the scope of our analysis, other than to state that lacking either definitive evidence exonerating selected types of fine particles or quantitative evidence supporting relative toxicities, an assumption of equal toxicity is a reasonable default for a central estimate.

\section{Economic Implications}

Although the economic valuation of health endpoints is highly uncertain, we apply the central estimates used in the US EPA benefit-cost analyses [16,17] to illustrate the potential magnitude of externalities avoided in relation to the direct economic savings.

Based on the findings of a number of labor market and contingent valuation studies, the US EPA determined a value of statistical life of $\$ 4.8$ million in 1990 US dollars, which can be translated into an approximate value of $\$ 6$ million in 2000 US dollars using Consumer Price Index inflation rates. We apply this value assuming a five-year lag structure for deaths from cohort mortality evidence [16], with $25 \%$ of deaths in each of the first two years and $16.7 \%$ of deaths in the subsequent three years.

In the benefit-cost analysis of the Clean Air Act [16], an asthma attack is given a central value of $\$ 32$ (in 1990 dollars), based on a willingness to pay study that focused on avoidance of a bad asthma day. To our knowledge, no willingness to pay study has been conducted on restricted activity days. Given values reported in the benefit-cost analysis of the Clean Air Act [16] of $\$ 38$ for a minor restricted activity day (which is more mild than a restricted activity day) and $\$ 83$ for a work-loss day (which is presumably more severe than a restricted activity day), we use $\$ 60$ (in 1990 dollars) as a reasonable central estimate. In the Discussion, we focus on the sensitivity of conclusions to the approach for valuation of premature mortality.

To quantify the incremental cost of insulation, we determined the average R-value increase in ceiling, walls, and foundations, and used this to quantify the volume of insulation required per home, given the square footage of 
Table 2: Regional energy savings for existing single-family homes increasing insulation from current practice to IECC 2000 levels.

\begin{tabular}{|c|c|c|c|c|c|}
\hline & Northeast (NE/MA) & Midwest (ENC/WNC) & South (SA/ESC/WSC) & West (MTN/PA) & Total \\
\hline \multicolumn{6}{|l|}{ All-electric homes } \\
\hline \# households (millions) & 1.0 & 1.6 & 11 & 3.8 & 17 \\
\hline $\begin{array}{l}\text { Source savings (TBTU/year, \% of national } \\
\text { total) }\end{array}$ & 15 (5\%) & $31(11 \%)$ & $190(69 \%)$ & $4 \mid(15 \%)$ & 280 \\
\hline $\begin{array}{l}\text { Per-capita savings (MMBTU/household/ } \\
\text { year) }\end{array}$ & 15 & 20 & 17 & II & 16 \\
\hline \multicolumn{6}{|l|}{ Non-electric heated homes } \\
\hline \# households (millions) & 6.5 & 9.9 & 7.5 & 5.3 & 29 \\
\hline $\begin{array}{l}\text { Source savings, fossil fuel (TBTU/year, \% } \\
\text { of national total) }\end{array}$ & $130(26 \%)$ & $220(46 \%)$ & $97(20 \%)$ & $43(9 \%)$ & 490 \\
\hline $\begin{array}{l}\text { Source savings, electricity (TBTU/year, \% } \\
\text { of national total) }\end{array}$ & $0.43(2 \%)$ & $1.6(6 \%)$ & $25(89 \%)$ & $0.98(3 \%)$ & 28 \\
\hline $\begin{array}{l}\text { Source savings, total (TBTU/year, } \% \text { of } \\
\text { national total) }\end{array}$ & $130(24 \%)$ & $230(44 \%)$ & $120(24 \%)$ & $44(8 \%)$ & 520 \\
\hline $\begin{array}{l}\text { Per-capita savings(MMBTU/household/ } \\
\text { year) }\end{array}$ & 19 & 23 & 16 & 8.3 & 18 \\
\hline
\end{tabular}

Note: Estimates are presented to two significant figures; sums may not add due to rounding. Percentages represent the fraction of benefits within each region.

the homes and the assumption that 0.3 inches of fiberglass corresponds to a unit increment in R-value. We quantified the value of insulation in dollars per ton, based on the reported value of shipment from the mineral wool sector [29] and the mass of fiberglass production [30], along with an assumed density of fiberglass of $0.06 \mathrm{~kg} / \mathrm{in}$ $\mathrm{ft}^{2}$. Annual economic savings associated with the energy reductions were based on state-level unit prices for electricity, natural gas, and fuel oil [31]. The real prices of all fuels were assumed to be constant over time, given forecasts of relatively small price changes in upcoming decades [32]. For all net present value calculations, we apply a 5\% real discount rate, the central estimate used in US EPA benefit-cost analyses [16].

\section{Results \\ Energy Savings}

Prior to calibration, our predictive regression models based on REM/Design outputs systematically overpredicted energy consumption as summarized in RECS. We considered performance stratified by fuel type and combinations of census divisions, where Northeast corresponds to NE and MA; Midwest to ENC and WNC; South to SA, ESC, and WESC; and West corresponds to MTN and PA (Table 1). Natural gas and fuel oil consumption were within $10 \%$ of reported values in all regions but the West, where the regression model predicted energy consumption 1.7 times higher than that reported in RECS. The bias was somewhat greater for electricity consumption (a factor of 1.4-2.6 higher across regions for gas- or oil-heated homes and a factor of 2.4-3.4 higher for electric-heated homes). As described in our earlier analysis [7], REM/Design has been shown to somewhat overestimate energy consumption, so this performance and the need for a calibration factor were anticipated. We calibrated the model by simply multiplicatively scaling the regression results to reported RECS values, stratified by region and fuel type.

According to our calibrated energy model, increasing residential insulation in the 46 million existing homes where insulation retrofits are necessary would save approximately 800 TBTU per year - 17 MMBTU $\left(1.7 \times 10^{7}\right.$ BTU $)$ per household per year. Of this total, $39 \%$ is related to source electricity savings, with $52 \%$ related to natural gas and $10 \%$ to fuel oil. Approximately $80 \%$ of the source electricity savings are associated with space heating rather than cooling. Thirty-five percent of energy savings occurs in electric-heated homes, with the remainder occurring in gas- or fuel oil-heated homes (either through reduced fossil fuel combustion or reduced electricity consumption for space cooling).

Looking at regional patterns, within electric-heated homes, nearly $70 \%$ of the energy savings are found in the South, principally due to the number of electric-heated homes in the South relative to other regions (Table 2). On a per unit basis, the savings are greatest in the Midwest and lowest in the West, related to climate and current practice insulation levels. For homes heated by natural gas or fuel oil, nearly half of the energy savings are found in the Midwest, given both the number of households and the higher per unit energy savings. Across all fuel types, the annual per unit energy savings for retrofitting existing homes are approximately four times greater than the per unit energy savings associated with increasing insulation from current practice levels in new homes to IECC 2000 
Table 3: Regional emission reductions for existing single-family homes increasing insulation from current practice to IECC 2000 levels.

\begin{tabular}{|c|c|c|c|c|c|}
\hline & Northeast (NE/MA) & Midwest (ENC/WNC) & South (SA/ESC/WSC) & West (MTN/PA) & Total \\
\hline \multicolumn{6}{|l|}{$\begin{array}{l}\mathrm{PM}_{2.5} \text { (tons/year, \% of } \\
\text { national total) }\end{array}$} \\
\hline Electricity & $82(4 \%)$ & $260(12 \%)$ & $1,600(74 \%)$ & $210(10 \%)$ & 2,100 \\
\hline Residential (NG + Oil) & $210(21 \%)$ & $480(49 \%)$ & $200(20 \%)$ & $94(10 \%)$ & 990 \\
\hline Total & $290(9 \%)$ & $740(24 \%)$ & $1,800(57 \%)$ & $300(10 \%)$ & 3,100 \\
\hline \multicolumn{6}{|l|}{$\begin{array}{l}\mathrm{SO}_{2} \text { (tons/year, \% of } \\
\text { national total) }\end{array}$} \\
\hline Electricity & $9,100(5 \%)$ & $21,000(12 \%)$ & $130,000(78 \%)$ & $8,300(5 \%)$ & 170,000 \\
\hline Residential (NG + Oil) & $14,000(69 \%)$ & $3,000(15 \%)$ & $3,100(15 \%)$ & $260(1 \%)$ & 20,000 \\
\hline Total & $23,000(12 \%)$ & $24,000(12 \%)$ & $140,000(7 \mid \%)$ & $8,600(4 \%)$ & 190,000 \\
\hline \multicolumn{6}{|l|}{$\begin{array}{l}\text { NOx (tons/year, \% of } \\
\text { national total) }\end{array}$} \\
\hline Electricity & $2,900(4 \%)$ & $9,300(12 \%)$ & $57,000(74 \%)$ & $7,500(10 \%)$ & 77,000 \\
\hline Residential (NG + Oil) & $6,800(28 \%)$ & $1 \mathrm{I}, 000(44 \%)$ & $4,700(20 \%)$ & $2,000(8 \%)$ & 24,000 \\
\hline Total & $9,700(10 \%)$ & $20,000(20 \%)$ & $62,000(61 \%)$ & $9,500(9 \%)$ & 100,000 \\
\hline
\end{tabular}

Note: Estimates are presented to two significant figures; sums may not add due to rounding. Percentages represent the fraction of benefits within each region.

code levels [7], a finding that agrees with other analyses [13].

An evaluation at the state level can provide some insight about differentials in past energy codes as well as withinregion differences that might be important from an emissions and exposure perspective. Unsurprisingly, the states with the greatest total energy savings generally correspond to the states with the most households - Texas, New York, Michigan, Illinois, and Ohio represent $28 \%$ of the national energy savings (and 25\% of the total households). On a per unit basis, the states with the greatest energy savings are North Dakota, Minnesota, West Virginia, and South Dakota, while the smallest per unit savings are seen in Arizona, New Mexico, Florida, and California, a clear indication of the importance of climate.

\section{Emission Reductions}

Given these energy savings, the aggregate emission reductions from residential fuel combustion and power plants include approximately 3,100 fewer tons per year of $\mathrm{PM}_{2.5}$, 100,000 fewer tons per year of NOx, and 190,000 fewer tons per year of $\mathrm{SO}_{2}$ (Table 3 ). For all three pollutants, the majority of emissions are linked to power plants $(69 \%$ for $\mathrm{PM}_{2.5}, 76 \%$ for $\mathrm{NOx}$, and $89 \%$ for $\mathrm{SO}_{2}$ ), even though only $39 \%$ of energy savings is related to electricity generation. This can be explained by the predominance of natural gas space heating, which has lower emissions of all pollutants (particularly $\mathrm{SO}_{2}$ ) when compared with electricity generation from marginal power plants that are often fueled by coal.
When we consider tons of pollutants emitted per unit energy savings across regions, it is clear that there are substantial regional variations in emissions intensity of energy consumption (Figure 2). For primary $\mathrm{PM}_{2.5}$, emissions per unit energy savings are similar across regions for residential fuel combustion, but are somewhat greater in the Midwest and the South for electricity. Similarly, for $\mathrm{SO}_{2}$, the electricity-related emissions are greater in other regions than in the West, where a greater proportion of electricity available on the margin is generated by natural gas. For residential fuel combustion, the emissions intensity for $\mathrm{SO}_{2}$ is far lower than that for electricity, with the exception of the Northeast, where fuel oil combustion is more prevalent. Finally, the emissions intensity patterns for NOx are broadly consistent with those for $\mathrm{PM}_{2.5}$, indicating similarities in the ratios of emission rates associated in part with combustion temperature and efficiency.

The rankings of states, both on an aggregate basis and on a per unit basis, differ when energy savings are translated into emissions reductions. First considering aggregate emission reductions, for $\mathrm{PM}_{2.5}$, the highest-emitting states are those larger states with substantial electric space heating and higher-emitting power plants - Texas, Virginia, North Carolina, and Tennessee. The top four emitting states are identical for NOx, with Maryland having the highest emissions of $\mathrm{SO}_{2}$ (followed by Virginia, North Carolina, and Tennessee). On a per unit basis, West Virginia, Kentucky, Delaware, and Virginia have the highest emissions for $\mathrm{PM}_{2.5}$ and $\mathrm{NOx}$, with Delaware, West Virginia, Maryland, and Kentucky having the highest $\mathrm{SO}_{2}$ emissions. 

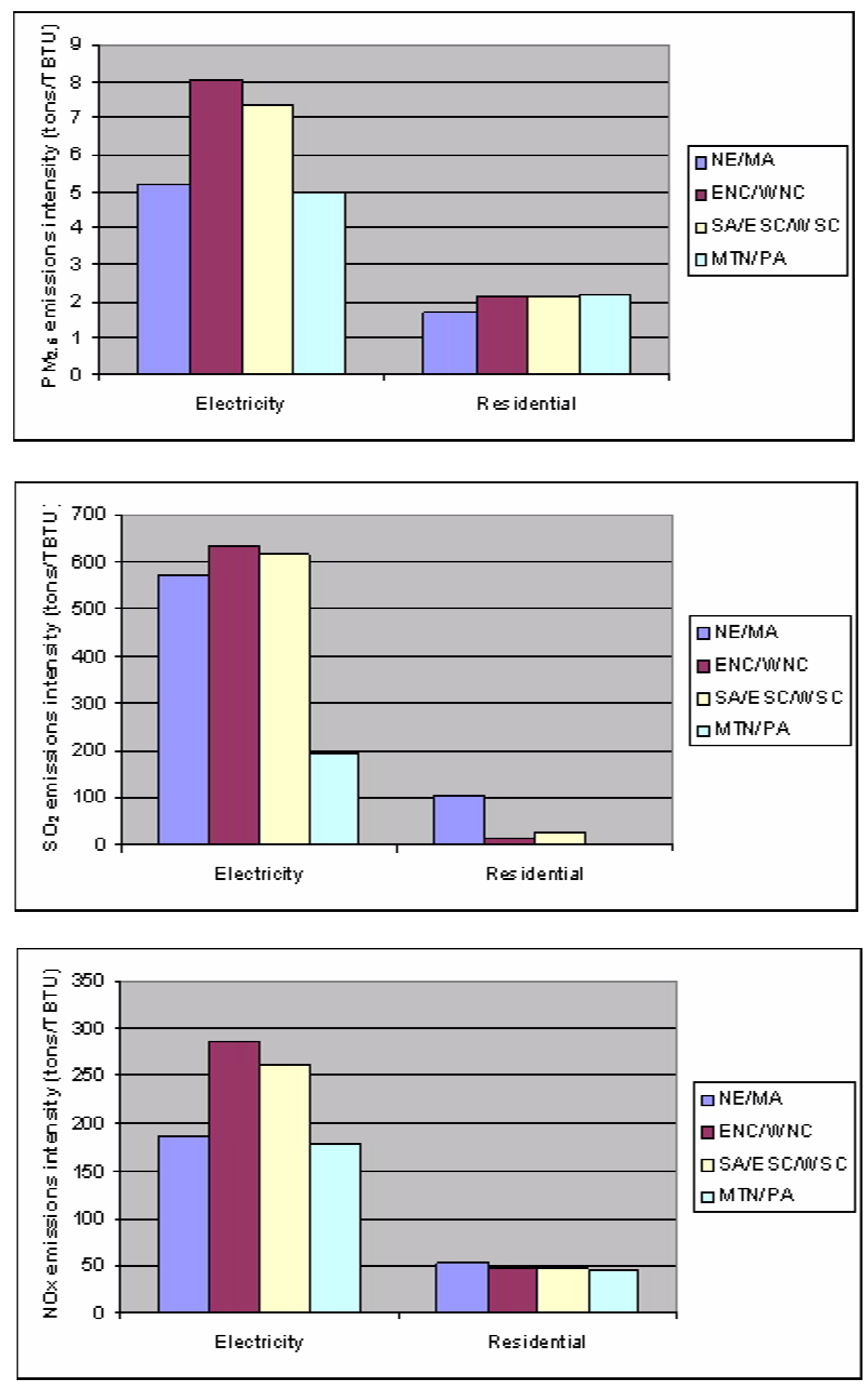

Figure 2

Emissions intensities of electricity and residential fuel combustion stratified by region (tons/TBTU of source energy). 
Table 4: Regional mortality reductions for existing single-family homes increasing insulation from current practice to IECC 2000 levels.

\begin{tabular}{|c|c|c|c|c|c|}
\hline & Northeast(NE/MA) & Midwest(ENC/WNC) & South(SA/ESC/WSC) & West(MTN/PA) & Total \\
\hline \multicolumn{6}{|l|}{$\begin{array}{l}\mathrm{PM}_{2.5} \text { (deaths/year, \% of } \\
\text { national total) }\end{array}$} \\
\hline Electricity & $2.2(7 \%)$ & $3.2(11 \%)$ & $23(76 \%)$ & $1.6(5 \%)$ & 30 \\
\hline Residential (NG + Oil) & $18(34 \%)$ & $22(43 \%)$ & $10(19 \%)$ & $2.1(4 \%)$ & 52 \\
\hline Total & $20(24 \%)$ & $26(31 \%)$ & 33 (40\%) & $3.7(5 \%)$ & 82 \\
\hline \multicolumn{6}{|c|}{$\begin{array}{l}\mathrm{SO}_{2}-\text { Sulfate (deaths/year, } \% \\
\text { of national total) }\end{array}$} \\
\hline Electricity & $6.9(5 \%)$ & $16(13 \%)$ & $100(79 \%)$ & $3.8(3 \%)$ & 130 \\
\hline Residential (NG + Oil) & 12 (72\%) & $2.4(15 \%)$ & $2.1(13 \%)$ & $0.1(0.5 \%)$ & 16 \\
\hline Total & $18(13 \%)$ & $19(13 \%)$ & $100(72 \%)$ & $3.9(3 \%)$ & 140 \\
\hline \multicolumn{6}{|c|}{$\begin{array}{l}\text { NOx - Nitrate (deaths/year, } \\
\% \text { of national total) }\end{array}$} \\
\hline Electricity & $0.5(5 \%)$ & I.I (12\%) & $6.4(66 \%)$ & $1.7(18 \%)$ & 9.7 \\
\hline Residential (NG + Oil) & I.I (32\%) & $1.6(46 \%)$ & $0.5(15 \%)$ & $0.2(7 \%)$ & 3.3 \\
\hline Total & $1.5(12 \%)$ & $2.7(20 \%)$ & $6.9(53 \%)$ & $1.9(15 \%)$ & 13 \\
\hline \multicolumn{6}{|l|}{$\begin{array}{l}\text { Total (deaths/year, } \% \text { of } \\
\text { national total) }\end{array}$} \\
\hline Electricity & $9.5(6 \%)$ & $20(12 \%)$ & $130(78 \%)$ & $7.1(4 \%)$ & 170 \\
\hline Residential (NG + Oil) & $30(42 \%)$ & $26(37 \%)$ & $13(18 \%)$ & $2.4(3 \%)$ & 72 \\
\hline Total & $40(17 \%)$ & 47 (20\%) & $140(60 \%)$ & $9.5(4 \%)$ & 240 \\
\hline
\end{tabular}

Note: Estimates are presented to two significant figures; sums may not add due to rounding. Percentages represent the fraction of benefits within each region.

\section{Public Health Benefits}

Using our intake fraction estimates and concentration-response functions for mortality and morbidity, the emission reductions of particulate matter and particle precursors can be translated into health benefits. In total, the emission reductions correspond to 240 fewer deaths, 6500 fewer asthma attacks, and 110,000 fewer restricted activity days per year, spread across the continental US. This represents an approximate $0.01 \%$ decrease in rates of the selected mortality and morbidity outcomes. The distribution of mortality benefits by pollutant, source, and region is presented in Table 4, with identical patterns seen for the morbidity outcomes.

Of the 240 annual deaths averted, more than half are associated with reduced sulfate exposures due to $\mathrm{SO}_{2}$ emission reductions. This is largely due to reduced electricity consumption for space heating in the South. Approximately $34 \%$ of the health benefits are related to primary $\mathrm{PM}_{2.5}$ emission reductions, largely due to reduced residential fuel combustion in the Northeast and Midwest and reduced electricity consumption in the South. Nitrate particles due to NOx emissions play a relatively minor role, contributing only $5 \%$ of total benefits.

Because of differences in regional emissions intensities, meteorological conditions influencing pollutant fate and transport, and population patterns, the distribution of health benefits across regions and states differs signifi- cantly from the distribution of energy savings. On a regional basis, although the South provides only 39\% of total energy savings, it is responsible for nearly $60 \%$ of public health benefits. In contrast, the West provides $11 \%$ of total energy savings but only $4 \%$ of public health benefits. As shown in Figure 3, the relative contributions of states to energy savings versus public health benefits also vary substantially. States that contribute proportionately more to mortality reductions than to energy savings (e.g., Virginia, North Carolina, Tennessee) tend to have significant electric space heating with electricity from power plants that emit higher amounts of $\mathrm{SO}_{2}$.

Looking at the benefits on a per capita basis, there are significant differences across states in both public health and energy savings (Figure 4). The two figures are moderately correlated with one another $(\mathrm{r}=0.50)$, with a ratio that varies by a factor of ten (with a minimum mortality reduction per unit energy savings in North Dakota and a maximum in Maryland). This provides tangible evidence that one cannot simply calculate public health benefits given estimated energy savings, as population density, climate, fuel usage, and emissions intensities significantly affect estimated health benefits.

\section{Economic Implications}

In total, the estimated cost of the increased insulation is approximately $\$ 37$ billion US, or an average of slightly below $\$ 800$ per existing single-family home available for 


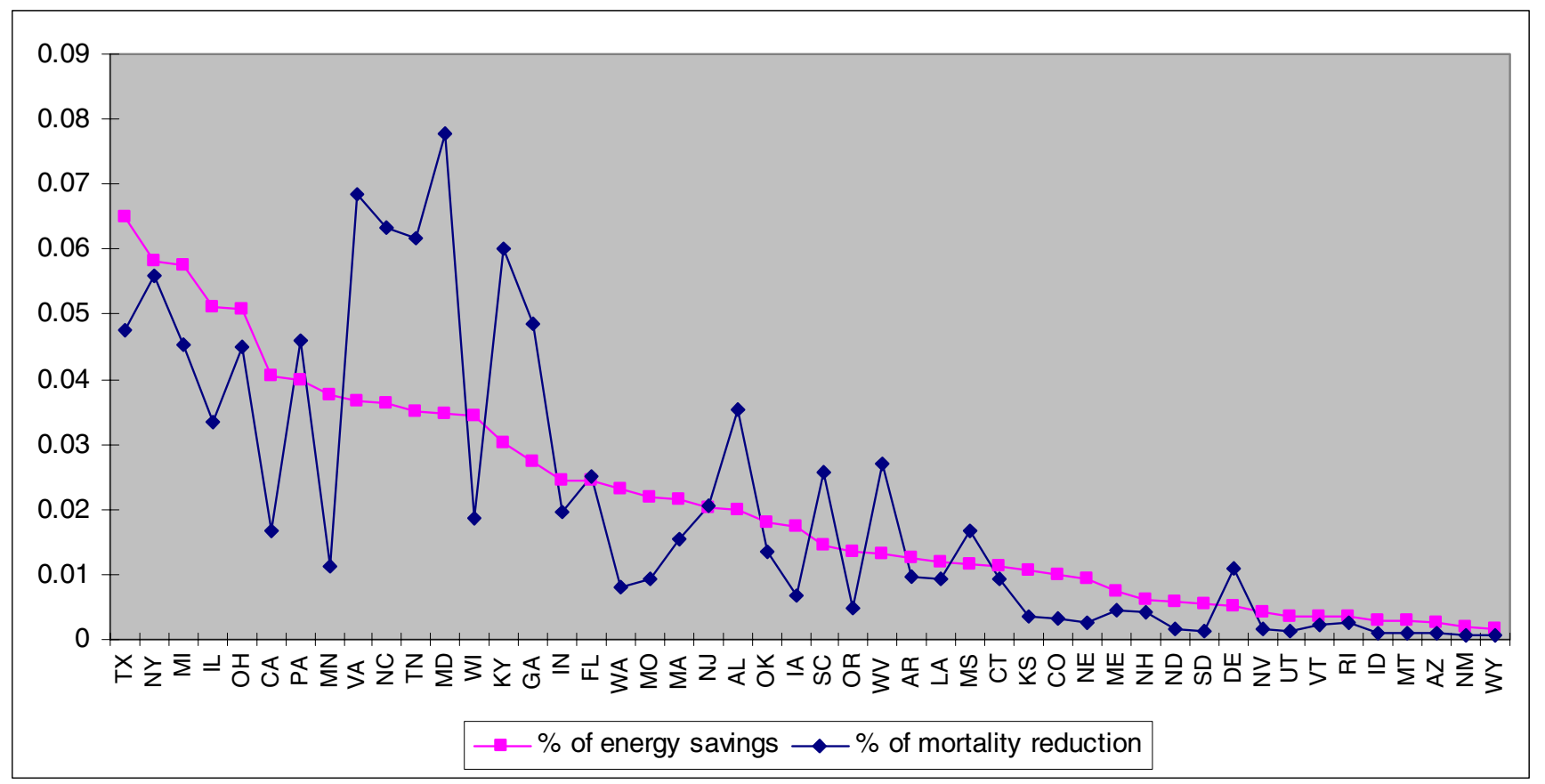

\section{Figure 3}

Percent contribution of states to energy savings and mortality reductions.

retrofits. The annual economic benefits associated with the energy savings are approximately $\$ 5.9$ billion per year, indicating a payback period of slightly over 6 years (assuming no change in the real price of fuel). Since this includes an array of homes in different regions and with different baseline insulation levels, the payback period clearly varies substantially across homes. If we apply a real discount rate of $5 \%$, then the net present value of the economic savings (conservatively assuming a 50-year lifetime for all homes) is approximately $\$ 110$ billion, implying a net economic savings (including the cost of insulation) on the order of $\$ 80$ billion.

When economic values are assigned to the mortality and morbidity outcomes as described above, the environmental externalities averted through increased insulation amount to approximately $\$ 1.3$ billion per year. Over $99 \%$ of this total is related to premature mortality, indicating that the assumed value of statistical life is a key parameter in this calculation (although not all morbidity outcomes were included in our analysis). Adding this quantity to the economic savings for the households would reduce the payback period from over 6 years to approximately 5 years, although this involves combining private and public benefits, has a simple characterization of the time lag of benefits, and does not include the upstream emissions from insulation manufacturing or fuel extraction and processing. Nevertheless, this calculation provides a rough indication of the relative magnitudes of environmental externalities and cost savings.

\section{Discussion}

Our analysis has demonstrated that it is viable to calculate central estimates for the public health benefits associated with reduced residential energy consumption, making use of previous dispersion models and epidemiological studies. Our model can provide insight about the relative merits of alternative energy efficiency policies, as well as allowing for a comparison with source controls or other public health interventions. For example, our central estimate of 240 fewer premature deaths per year from retrofitting existing homes can be compared with 1.1 fewer premature deaths per year from increasing insulation in a single year of new homes [7]. The ratio between these values is greater than 200, which exceeds the energy savings ratio of approximately 130, illustrating the importance of 


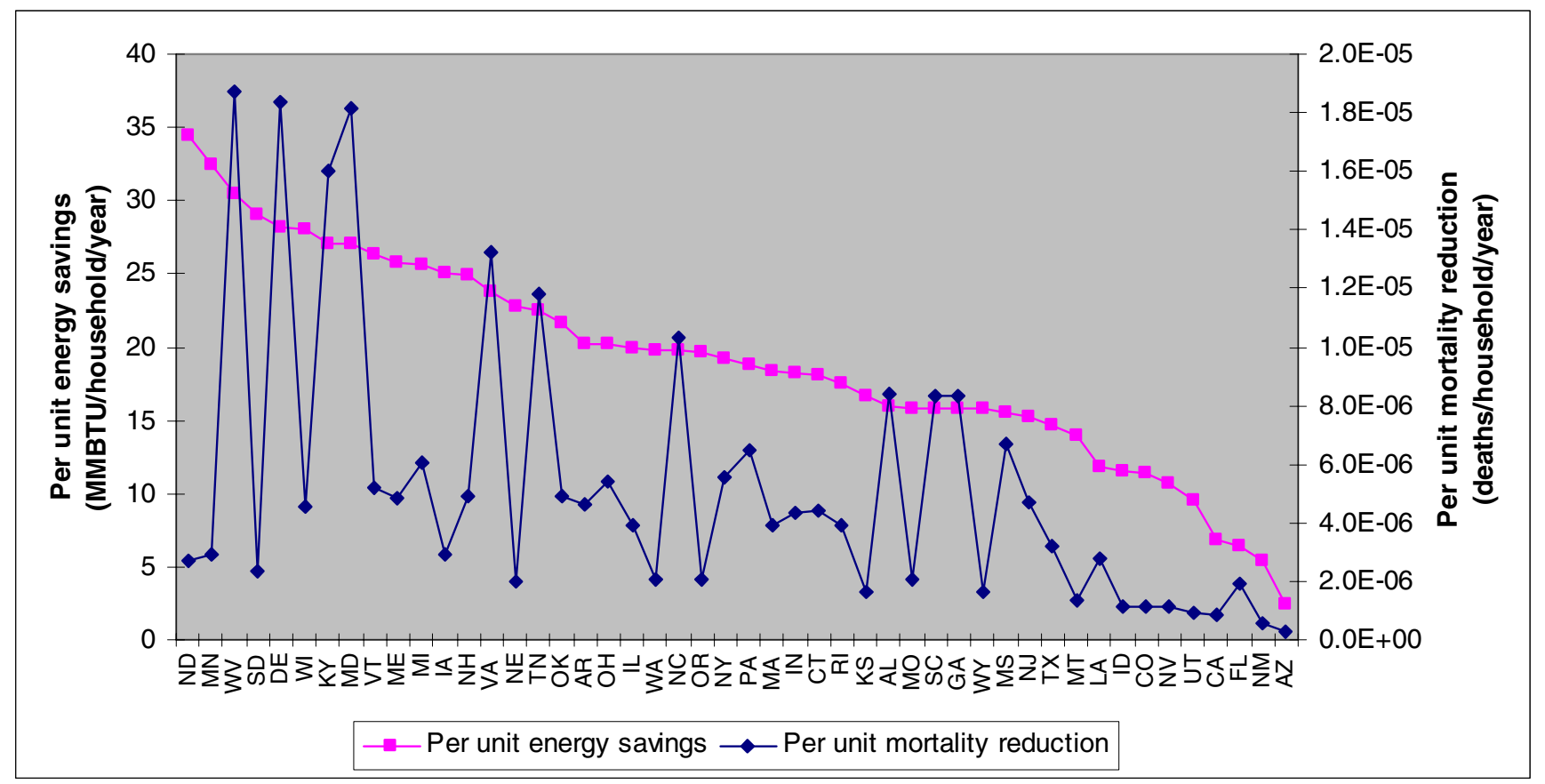

\section{Figure 4}

Per unit energy savings and mortality reductions by state.

geographic patterns of housing starts. The differential between these values clearly demonstrates the substantially greater potential in the existing housing market, even given the fact that existing home retrofits represent a "one time" opportunity, while housing codes influencing new homes would affect construction over multiple years.

To provide further context about the magnitude of benefits, retrofitting one million existing homes today would have the same public health benefits as requiring 5.7 million new homes to meet IECC 2000 standards. Given the rate of new home construction (approximately 1.2 million new homes per year), this implies that a code change today would yield identical annual benefits as the one million home retrofit in about 5 years, with identical cumulative benefits in 9 years. In addition, a recent study estimated that requiring nine older ("grandfathered") coalfired power plants in Illinois to meet new source standards would yield approximately 300 fewer premature deaths per year [3], similar to the benefits of retrofitting all eligible existing homes. Cost-effectiveness comparisons with other interventions are not very useful, as increased residential insulation both reduces aggregate costs (calculated as net present value) and health risks, given the boundaries of our analysis.
While these comparisons provide some insight about the implications of our analysis, any risk-based calculation is deficient without careful quantitative consideration of the uncertainties inherent in the estimates. We have deemed a formal uncertainty analysis to be beyond the scope of our investigation, in part because uncertainties have been discussed elsewhere [7] and in part because it is difficult to accurately quantify many core uncertainties. However, we can use the findings of our analysis to provide some qualitative prioritization of future areas of study. We summarize the findings of our qualitative uncertainty analysis in Table 5, which draws on past damage function uncertainty characterization [4].

First, if the environmental externalities represent the endpoint of our analysis, it is clear that resolving uncertainties related to mortality will be more important than resolving uncertainties related to morbidity. However, this is partly dependent on our underlying health and valuation assumptions. We have used the cohort mortality studies and a value of statistical life (VSL) approach. An extreme lower-bound calculation for mortality would first focus on the time-series rather than cohort mortality evidence. This decision could either be based on the belief that there is inadequate evidence of a long-term mortality effect (although reliance on cohort evidence has been supported 
Table 5: Qualitative uncertainty characterization for demand-side management health benefits model, focusing on key model assumptions.

\begin{tabular}{|c|c|c|c|}
\hline Model Component & Model Assumption & $\begin{array}{l}\text { Likely Magnitude of } \\
\text { Uncertainty }\end{array}$ & Effect of Alternative Assumptions \\
\hline \multirow[t]{3}{*}{ Energy model } & $\begin{array}{c}\text { Insulation retrofits viable in } 63 \% \text { of homes, uniformly distributed } \\
\text { nationally }\end{array}$ & small & - \\
\hline & Use of regression model to estimate REM/Design outputs & small & - \\
\hline & Calibration of regression model outputs to RECS data & small & - \\
\hline \multirow[t]{4}{*}{ Emissions reductions } & $\begin{array}{c}\text { All marginal power plants equally likely to be affected by change in } \\
\text { electricity consumption }\end{array}$ & medium & Capacity- or availability-based allocation $(\uparrow)$ \\
\hline & Use of AP-42 emissions data for residential fuel combustion & medium & - \\
\hline & $\begin{array}{c}\text { Constant emissions from power plants and residential fuel combustion } \\
\text { over time }\end{array}$ & medium & $\begin{array}{l}\text { Emissions decrease over time given regulations } \\
\qquad(\downarrow)\end{array}$ \\
\hline & Focus on air emissions of $\mathrm{PM}, \mathrm{NOx}, \mathrm{SO}_{2}$ & small & Include other criteria pollutants, air toxics $(\uparrow)$ \\
\hline \multirow[t]{3}{*}{ Intake fractions } & $\begin{array}{c}\text { Use of regression model estimates for intake fractions for power } \\
\text { plants }\end{array}$ & unknown & - \\
\hline & $\begin{array}{l}\text { Use of regression model estimates for primary PM intake fractions for } \\
\text { residential combustion }\end{array}$ & large & $\begin{array}{l}\text { Apply dispersion model with more refined spa- } \\
\text { tial resolution }(\uparrow)\end{array}$ \\
\hline & $\begin{array}{l}\text { Use of regression model estimates for secondary PM intake fractions } \\
\text { for residential combustion }\end{array}$ & unknown & - \\
\hline \multirow[t]{4}{*}{ Health evidence } & $\begin{array}{c}\text { Use of American Cancer Society cohort evidence to estimate mortality } \\
\text { risks from PM }\end{array}$ & large & $\begin{array}{c}\text { Use results from Six Cities Study }(\uparrow) \text {; use only } \\
\text { time-series evidence }(\downarrow)\end{array}$ \\
\hline & Equal toxicity of all particles & large & - \\
\hline & Linear concentration-response function with no threshold & unknown & Assume threshold at $\mathrm{PM}_{2.5}$ annual NAAQS $(\downarrow)$ \\
\hline & Inclusion of only asthma attacks, restricted activity days for morbidity & medium & Incorporate other morbidity outcomes $(\uparrow)$ \\
\hline \multirow[t]{2}{*}{ Valuation } & Use of VSL of $\$ 6$ million for mortality & large & - \\
\hline & Constant real price of fuel over time & small & - \\
\hline \multirow[t]{2}{*}{ Model framework } & Focus only on public health & medium & $\begin{array}{c}\text { Include greenhouse gases, dependence on oil } \\
\text { imports, etc. }(\uparrow)\end{array}$ \\
\hline & Focus only on emissions reductions from energy savings & medium & $\begin{array}{l}\text { Include emissions from insulation manufacturing, } \\
\text { occupational risks, indoor air quality, etc. }(\downarrow)\end{array}$ \\
\hline
\end{tabular}

Note: $\downarrow$ indicates that alternative assumption would likely reduce the net benefit estimate; $\uparrow$ indicates that alternative assumption would likely increase the net benefit estimate

elsewhere $[33,34])$ or the belief that long-term effects involve significant lags and near-term benefits might therefore dominate externality estimates. Given this focus, an additional lower-bound assumption would consider a life-year measure more appropriate than a VSL measure, with a relatively short longevity loss assumed in the timeseries studies.

Using a value from the time-series literature of an approximate $1 \%$ increase in deaths per $10 \mu \mathrm{g} / \mathrm{m}^{3}$ increase in $\mathrm{PM}_{2.5}[27,35,36]$, assuming that each time-series death represents a loss of only one life-year, and using US EPA's value of statistical life year of $\$ 360,000$ [17], our annual mortality benefit would be decreased from $\$ 1.3$ billion to $\$ 30$ million. In this extreme case, mortality still represents $77 \%$ of the benefits (albeit with a limited set of morbidity outcomes). With the inclusion of the suite of common morbidity outcomes (including chronic respiratory disease and hospitalizations for cardiovascular or respiratory disease), morbidity would likely dominate monetized health benefits in this scenario.

Given the magnitude of this change, it is clear that improved understanding of the cohort mortality findings would be paramount in refining the estimates within our analysis. Of similar importance would be issues related to the relative toxicity of sulfate particles, nitrate particles, and primary combustion particles from various sources. According to our analysis, a majority of the benefits is associated with sulfate particles, indicating that alternative sulfate toxicities would strongly influence our findings. On the other hand, since nitrate particles contribute only $5 \%$ of benefits, changes in conclusions about nitrate toxicity would not influence our aggregate calculations in a substantial way. Appropriate economic values for premature mortality would clearly be critical as well. However, improved understanding about cohort mortality effects and life-years lost within epidemiological studies would greatly inform valuation, with a significant portion of the remaining uncertainty related to a value judgment about whether health outcomes should be valued on a life-year lost or willingness to pay basis.

Other significant contributors to uncertainty include the intake fraction estimates, the emissions characterizations, and the predictive energy models. Given the relative importance of $\mathrm{SO}_{2}$ emissions in the South, the sulfate intake fractions in this region would be most important to resolve. A recent analysis found that sulfate intake fractions for power plants in Georgia were similar when CALPUFF and an alternative dispersion model were applied [37], indicating that our estimates may not be sig- 
nificantly biased. However, for residential fuel combustion, the uncertainties may be somewhat greater. Mobile source intake fractions may not be identical to residential intake fractions, and the values applied may be underestimates, given the importance of near-source impacts and the relatively low geographic resolution of models underlying our intake fraction estimates [22]. The lack of characterization of the influence of $\mathrm{SO}_{2}$ emissions on nitrate concentrations also contributes uncertainty, although this is likely a relatively small bias on an annual average and nationally integrated basis.

Our methods for energy savings and emission reduction estimation also contribute uncertainties to the analysis, although many of these uncertainties are likely insignificant compared to the uncertainties articulated above. For example, since our energy models were both highly predictive of modeled energy consumption and were calibrated to reported energy consumption stratified by fuel type and region, significant bias is unlikely. This is illustrated by the fact that our aggregate energy savings estimate is within $20 \%$ of the value reported in a similar analysis [13], with the difference explained in part by differences in the assumed number of homes eligible for increased insulation.

On the emissions side, many uncertainties are difficult to quantify, since AP-42 does not provide quantitative estimates of variability or uncertainty. Our assumption about the allocation of electricity reductions across power plants could have contributed a downward bias, with an availability-based allocation increasing benefits to 510 fewer deaths per year and a capacity-based allocation increasing benefits to 720 fewer deaths per year. This could theoretically represent a significant uncertainty, and one that could be resolved with more detailed power sector models. One piece of information provides an indication that our baseline analysis may be the most reasonable depiction of the marginal electricity sector. A marginal emissions analysis for the New England Power Pool (NEPOOL) indicates marginal emission rates of $2.6 \mathrm{lb} /$ MWh of NOx and $9.4 \mathrm{lb} / \mathrm{MWh}$ of $\mathrm{SO}_{2}$ in 1997 [38], the identical year as our E-GRID database. These emission rates are within $20 \%$ of our baseline values for the NPCC NERC region (which includes both NEPOOL and New York State), and are substantially lower than the emission rates from the availability-based or capacity-based allocation schemes.

A final uncertainty is related to the limited scope of our analysis. We focused largely on the PM-related mortality benefits of energy savings, but there are clearly numerous additional benefits, including reduced greenhouse gas emissions, health benefits related to other pollutants (such as ozone) or morbidity endpoints, decreased de- pendence on oil imports, and so forth. Although many of these endpoints are difficult to quantify, they clearly represent ancillary benefits of energy savings.

In addition to the analytical uncertainties, there are broader limitations in applying our findings for policy purposes. As mentioned earlier, the lack of formal life cycle calculations impairs drawing conclusions about the net public health benefits of increased residential insulation. However, assuming parallelism with a life cycle investigation in new housing $[9,10]$ would imply that the public health impacts of increased insulation manufacturing would be far less than the public health benefits of reduced energy consumption during the lifetime of the home, with a payback comparable to the economic payback period of 6 years. Furthermore, our analysis represents static conditions, although the housing market and emission factors from sources (among other assumptions) are quite dynamic. For example, if regulations were put into place restricting emissions from power plants, the public health benefits of energy efficiency measures would be reduced. In addition, insulation retrofits of this magnitude could have significant market influences. Although the energy savings only represent $1 \%$ of annual US energy consumption (given the focus on only a subset of the residential sector), the amount of insulation required is substantially larger than the current annual insulation market. If all retrofits occurred in a relatively short period, this would significantly influence the unit price of insulation. Thus, although reduced energy consumption will have long-term public health implications, the uncertainties in benefit calculations likely increase as a function of time.

In spite of the uncertainties in our analysis, our study provides findings with potential policy implications and demonstrates some important methodological advancements in quantifying the public health benefits of energy efficiency programs. On the former point, although it is clear that a regulation mandating energy efficiency retrofits in existing homes would not be tenable, the magnitude of the economic and public health benefits indicates that creative public policies to encourage retrofits (e.g., low-interest loans or tax deductions) may be warranted. On the methodological side, the application of a regression model to estimate energy savings appeared reasonable and illustrated the potential for evaluating numerous alternative scenarios without extensive simulations. The intake fraction methodology yielded exposure estimates that were both interpretable from a health perspective and implementable for a large-scale energy efficiency program. Although further study is needed to reduce some core uncertainties within the analysis, the model framework is sufficiently flexible to allow for the integration of new scientific information. 


\section{Conclusions}

We have developed and applied a model to quantify the public health benefits of reduced residential energy consumption. Retrofitting existing single-family homes in the US would yield an estimated 800 TBTU of annual energy savings, which corresponds to net present value economic gains of approximately $\$ 80$ billion and public health benefits that include 240 fewer premature deaths per year. While there are substantial uncertainties in many components of our health benefits model, our analysis demonstrates an approach for integrating environmental and public health benefits into energy efficiency policy analysis.

\section{List of abbreviations}

E-GRID - Emissions and Generation Resource Integrated Database

IECC 2000 - International Energy Conservation Code, year 2000

MMBTU - $10^{6}$ British Thermal Units

MSA - Metropolitan Statistical Area

NEPOOL - New England Power Pool

NERC - North American Electricity Reliability Council

$\mathrm{NOx}$ - nitrogen oxides

$\mathrm{PM}_{2.5}$ - fine particulate matter (particulate matter less than $2.5 \mu \mathrm{m}$ in aerodynamic diameter)

$\mathrm{PM}_{10}$ - particulate matter less than $10 \mu \mathrm{m}$ in aerodynamic diameter

RECS - Residential Energy Consumption Survey

$\mathrm{SO}_{2}$ - sulfur dioxide

TBTU - $10^{12}$ British Thermal Units

VSL - Value of statistical life

\section{Competing interests}

None declared.

\section{Authors' contributions}

JIL drafted the manuscript and assisted in the development of the analytical model; YN developed the model to estimate health benefits from energy savings; and JDS conceived of the original study and participated in design and coordination. All authors read and approved of the final manuscript.

\section{Acknowledgements}

This work was supported by the North American Insulation Manufacturers Association. We thank Patrick Hofstetter, Laura Lind, Douglas Norland,

Gregory Norris, and Andrew Wilson for their contributions to our earlier analysis, which provided the foundation for this work.

\section{References}

I. Jones T, Norland D and Prindle B Opportunity Lost: A National and State Analysis of the 1993 Model Energy Code Washington, DC, Alliance to Save Energy 1998,

2. Reddy BS and Parikh JK Economic and environmental impacts of demand side management programmes Energy Policy 1997, 25:349-356

3. Levy JI, Spengler JD, Hlinka D, Sullivan D and Moon D Using CALPUFF to evaluate the impacts of power plant emissions in Illinois: Model sensitivity and implications Atmospheric Environment 2002, 36:1063-1075

4. Levy JI and Spengler JD Modeling the benefits of power plant emission controls in Massachusetts Journal of the Air \& Waste Management Association 2002, 52:5-18

5. Abt Associates, ICF Consulting and E.H. Pechan Associates The Particulate-Related Health Benefits of Reducing Power Plant Emissions 2000, [http://www.cta.policy.net/fact/mortality/ mortalityabt.pdf]

6. European Commission ExternE: External Costs of Energy, Volume 3: Coal and Lignite Brussels, Directorate-Generale XII, Science, Research, and Development 1995,

7. Nishioka Y, Levy JI, Norris GA, Wilson A, Hofstetter P and Spengler JD Integrating risk assessment and life cycle assessment: A case study of insulation Risk Analysis 2002, 22:1003-1017

8. US Census Bureau Current Construction Reports: Housing Completions, December 2000 Washington, DC, US Department of Housing and Urban Development, US Department of Commerce, US Census Bureau 2000,

9. Nishioka Y, Levy JI, Norris GA, Bennett DH and Spengler JD A riskbased approach to health impact assessment for input-output analysis - Part I: Methodology International Journal of Life Cycle Assessment

10. Nishioka Y, Levy JI, Norris GA, Bennett DH and Spengler JD A riskbased approach to health impact assessment for input-output analysis - Part 2: Case study of insulation. International Journal of Life Cycle Assessment

II. US Department of Energy 200I Residential Energy Consumption Survey Washington, DC, Energy Information Administration 200I,

12. US Department of Energy A Look at Residential Energy Consumption in 1997 Washington, DC, Energy Information Administration 1999 ,

13. Norland D and Lind L Green and Clean: The Economic, Energy, and Environmental Benefits of Insulation Washington, DC, Alliance to Save Energy 200I,

14. US Department of Energy 1998 and 2000 IECC Climate Zone Maps and Prescriptive Packages 2002, [http://www.energycodes.gov/rescheck/packages iecc.stm]

15. American Society of Heating Refrigerating and Air-Conditioning ASHRAE Handbook of Fundamentals Atlanta, GA, American Society of Heating, Refrigerating and Air Conditioning Engineers, Inc. 1997,

16. US Environmental Protection Agency The Benefits and Costs of the Clean Air Act: 1990 to 2010 Washington, DC, Office of Air and Radiation 1999,

17. US Environmental Protection Agency Regulatory Impact Analysis - Control of Air Pollution from New Motor Vehicles: Tier 2 Motor Vehicle Emissions Standards and Gasoline Sulfur Control Requirements Washington, DC, Office of Air and Radiation 1999 ,

18. US Environmental Protection Agency Compilation of Air Pollution Emission Factors. AP-42, Fifth Edition, Volume I: Stationary, Point and Area Sources Research Triangle Park, NC, US EPA 1995 ,

19. US Department of Energy Technical Support Document: Energy Efficiency Standards for Consumer Products. Appendix K-2: Emissions Factors for Fuel Combustion from Natural Gas, LPG, and Oil-Fired Residential Water Heaters Washington, DC, Building Research and Standards Office 2000, 
20. US Environmental Protection Agency Emissions and Generation Resource Integrated Database (E-GRID97, Version I.I) 2000, [http://www.epa.gov/airmarkets/egrid/]

21. Bennett DH, McKone TE, Evans JS, Nazaroff WW, Margni MD, Jolliet $O$ and Smith KR Defining intake fraction Environmental Science and Technology Online 2002, 36:207A-2 I IA

22. Evans JS, Wolff SK, Phonboon K, Levy JI and Smith KR Exposure efficiency: An idea whose time has come? Chemosphere 2002, 49:|075-|09|

23. Levy Jl, Wolff SK and Evans JS A regression-based approach for estimating primary and secondary particulate matter intake fractions Risk Analysis 2002, 22:895-904

24. West JJ, Ansari AS and Pandis SN Marginal PM2.5: Nonlinear aerosol mass response to sulfate reductions in the Eastern United States Journal of the Air \& Waste Management Association 1999, 49:|4|5-1424

25. Pope CA, Burnett RT, Thun MJ, Calle EE, Krewski D, Ito K and Thurston GD Lung cancer, cardiopulmonary mortality, and long-term exposure to fine particulate air pollution Environmental Health Perspectives 2002, 287: | |32-I|4 |

26. Dockery DW, Pope CA, Xu X, Spengler JD, Ware JH, Fay ME, Ferris B. G. Jr. and Speizer FE An association between air pollution and mortality in six U.S. cities. New England Journal of Medicine 1993 329: $1753-1759$

27. Schwartz J, Laden F and Zanobetti A The concentration-response relation between $\mathrm{PM}(2.5)$ and daily deaths Environ Health Perspect 2002, I I 0:1025-1029

28. Daniels MJ, Dominici F, Samet JM and Zeger SL Estimating particulate matter-mortality dose-response curves and threshold levels: an analysis of daily time-series for the $\mathbf{2 0}$ largest US cities. American Journal of Epidemiology 2000, I 52:397-406

29. US Department of Commerce Mineral Wool Manufacturing 1997 Washington, DC, Economics and Statistics Administration 1999 ,

30. US Department of Energy Economic Profile and Trend: Glass Industry Analysis Brief 1999, [http://www.eia.doe.gov/emeu/mecs/ iab/glass/pagelb.html]

31. US Department of Energy Multi-State Data 2002, [http:// www.eia.doe.gov/emeu/states/ multi states.html]

32. US Department of Energy Annual Energy Outlook 2003 With Projections to $\mathbf{2 0 2 5}$ Washington, D.C., Energy Information Administration 2003,

33. Committee on Estimating the Health-Risk-Reduction Benefits of Proposed Air Pollution Regulations Estimating the Public Health Benefits of Proposed Air Pollution Regulations Washington, DC, National Research Council 2002,

34. World Health Organization Quantification of the Health Effects of Exposure to Air Pollution: Report of a WHO Working Group Bilthoven, Netherlands, European Centre for Environment and Health 2000,

35. Burnett RT, Brook J, Dann T, Delocla C, Philips O, Cakmak S, Vincent $R$, Goldberg MS and Krewski D Association between particulateand gas-phase components of urban air pollution and daily mortality in eight Canadian cities Inhalation Toxicology 2000, 12 Supp 4:15-39

36. Klemm RJ, Mason RM, Heilig CM, Neas LM and Dockery DW Is daily mortality associated specifically with fine particles? Data reconstruction and replication of analyses Journal of the Air \& Waste Management Association 2000, 50:1215-1222

37. Levy JI, Wilson AM, Evans JS and Spengler JD Estimation of primary and secondary particulate matter intake fractions for power plants in Georgia Environmental Science and Technology Online

38. ISO New England 1998 Marginal Emission Rate Analysis for the NEPOOL Environmental Planning Committee 2000, [http:// www.iso-ne.com/Planning Reports/Emissions/]

\section{Publish with Bio Med Central and every} scientist can read your work free of charge

"BioMed Central will be the most significant development for disseminating the results of biomedical research in our lifetime. "

Sir Paul Nurse, Cancer Research UK

Your research papers will be:

- available free of charge to the entire biomedical community

- peer reviewed and published immediately upon acceptance

- cited in PubMed and archived on PubMed Central

- yours - you keep the copyright
BioMedcentral 